Discussion Paper No. 16-050

Changing of the Guard:

Structural Change and Corporate Science in the Semiconductor Industry

Maikel Pellens and Antonio Della Malva

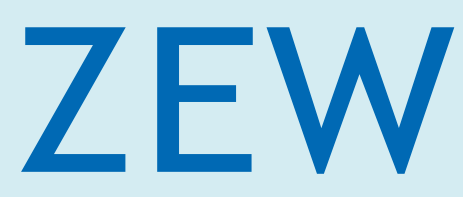

Zentrum für Europäische Wirtschaftsforschung $\mathrm{GmbH}$

Centre for European

Economic Research 


\section{Discussion Paper No. 16-050 \\ Changing of the Guard: Structural Change and Corporate Science in the Semiconductor Industry}

Maikel Pellens and Antonio Della Malva

Download this ZEW Discussion Paper from our ftp server:

http://ftp.zew.de/pub/zew-docs/dp/dp16050.pdf

Die Discussion Papers dienen einer möglichst schnellen Verbreitung von neueren Forschungsarbeiten des ZEW. Die Beiträge liegen in alleiniger Verantwortung der Autoren und stellen nicht notwendigerweise die Meinung des ZEW dar.

Discussion Papers are intended to make results of ZEW research promptly available to other economists in order to encourage discussion and suggestions for revisions. The authors are solely responsible for the contents which do not necessarily represent the opinion of the ZEW. 


\title{
Changing of the Guard: Structural Change and Corporate Science in the Semiconductor Industry
}

\author{
Maikel Pellens ${ }^{\mathrm{a}, \mathrm{b}}$ and Antonio Della Malva ${ }^{\mathrm{b}}$ \\ a) Centre for European Economic Research (ZEW), Mannheim (Germany) \\ b) KU Leuven, Dept. of Managerial Economics, Strategy, and Innovation, Leuven (Belgium)
}

\begin{abstract}
This article documents a structural change in the production of science in the U.S. semiconductor industry over almost three decades. We observe a change in scientific productivity over time, where smaller firms publish more articles per dollar in R\&D. Moreover, our results show a positive relationship between the value of intangibles and scientific publications, driven by basic research results. These effects are especially strong among Fabless 'design' firms and among firms in the post-PC era of semiconductor manufacturing, in line with a premium for smaller firms which invest in science in times of structural technological change.
\end{abstract}

JEL-Classification: $\mathrm{O} 31, \mathrm{O} 33$

Keywords: Corporate science, basic science, firm value, semiconductors

\section{Corresponding author:}

Maikel Pellens, Centre for European Economic Research, L 7, 1, 68161 Mannheim, Germany. Maikel Pellens: phone: +49 621123351 89, e-mail: pellens@zew.de Antonio Della Malva: phone: +32 16326 649, e-mail: Antonio.dellamalva@kuleuven.be Funding: This work was supported by the European Commission [grant number PIEP-2011302034].

Acknowledgements: The authors would like to thank ECOOM for excellent support in collecting the patent and publication data. Both authors thank comments on earlier drafts from Dirk Czarnitzki, Christian Rammer and Markus Simeth. Any errors remain the authors' own. 


\section{Introduction}

Corporate science is critical for competitiveness and sustainable growth, enhancing product and process innovation and a better integration of external knowledge into the firm (Griliches, 1981; Della Malva et al., 2015; Fleming and Sorenson, 2004; Cockburn and Henderson, 1998; Arora and Gambardella, 1994; Cohen and Levinthal, 1990; Rosenberg, 1990). Mostly concentrated in a handful of high-tech sectors related to the life sciences and electronics, the contribution of some firms to the public stock of science is comparable to world renowned academic departments: laboratories such as the Bell Labs, the RCA labs, Xerox Park and labs at IBM have been the birthplace of key scientific discoveries which have critically contributed to technological progress (Adams and Clemmons 2008; Cincera and Dratwa 2011; Pénin 2007).

Despite its advantages, corporate involvement in science is limited due to its susceptibility to knowledge spillovers stemming from the nature of scientific knowledge as well as the norms governing its production (Arrow 1962; Nelson 1959; Rosenberg 1990). A recent stream of research studies the involvement and returns from investments in science by firms. By focusing on a set of publicly listed firms from high-tech sectors, Simeth and Cincera (2015) estimated that corporate engagement in scientific research is positively associated with the valuation of intangible assets of firms, confirming that the benefits accruing from scientific research outweigh the potential costs. However, concerns exist that private corporations have been cutting back on science the last decades due to competitive pressures (Arora et al. 2015). The authors show that the number of publications in scientific journals by publicly listed US firms has decreased over time, advancing that globalization and a focus on core activities have led firms to value the returns on the investments in science, rather than investing in scientific capabilities. Recent evidence has highlighted a change in scientific investments by private firms: young, technologyintensive firms have started investing in basic science in the expectation of developing multiple applications, compensating for the retrenchment of older companies (Drake 2014).

We extend this line of research by studying how the type of science and sectoral evolutions affect the relationship between corporate science and the value of the intangible assets. In this respect, we analyze the performance and returns from investments in science by publicly listed U.S. semiconductor firms. The first contribution of our study is the focus on one single sector which allows us to understand how sectoral dynamics affect the publication behavior of firms. The semiconductor sector makes for an interesting setting because of its high $R \& D$ intensity and the extensive use of scientific methods and practices (Langlois and Steinmueller 1999; Lim 2004; Cohen et al. 2002). ${ }^{1}$ Moreover, the sector has

\footnotetext{
${ }^{1}$ Companies such as AT\&T, IBM, GE, and Texas Instruments have had Nobel laureates in Physics among their employees.
} 
experienced structural changes in its organization in the last decades. Whereas in the 80 s and early 90 s the sector developed in a cumulative fashion along the Wintel architectural standard and was primarily focused on applications related to personal computing, in the late 90 s the industry has undergone a fundamental transformation driven by the integration of multiple functionalities within the same device, the system-on-a-chip ( $\mathrm{SoC})$. New scientific challenges have emerged and new actors, fabless firms specialized in the design of SoC, have entered the market (Linden and Somaya 2003).

As a second contribution we distinguish between scientific articles with applied or basic character. Extant literature takes on a homogenous view of scientific publications as a unit of scientific knowledge. Yet not all science covers the same spectrum; it ranges from more basic to more applied. Basic research addresses puzzles with more general implications for scientific and technological development, whereas applied research instead deals mostly with the translation of scientific findings into viable commercial applications (NSF 2014). ${ }^{2}$ Since these differences clearly carry different potential costs and benefits for firms, the incentives for firms to carry out different types of research and their relationship to firm value should be assessed independently.

In line with previous studies (Lim 2004; Tijssen 2004), our data suggest that the production of science, and especially basic science, is more concentrated than the production of technology in the semiconductor sector. We identify a positive trend in the number of scientific articles authored by companies over time, notably among firms with low levels of $R \& D$ spending, who seem to compensate for decreasing publications by high $R \& D$ spending firms. A series of event studies indicates that the relationship between stock market value and scientific publications depends on the type and quality of science being produced. In a multivariate setting, we find a weak positive relationship between scientific publications by semiconductor firms in scientific literature and their market to book value ratio (Tobin's Q). When we differentiate between basic and applied knowledge, we find that only publishing in basic journals carries a strong positive market value premium, despite representing only $3 \%$ of the publications in our sample. These results are in line with the findings by Simeth and Cincera (2015), who found positive effects for high-tech Compustat firms, but not for the ICT sector. Arora et al. (2015) find a positive relationship between publication stock and market value, which however decreases over time.

Delving deeper in the evolution of the sector, we observe that the premium attached to science, and basic science in particular, mostly pertains to those firms which managed to exploit the transition to the "Post-PC" era in the last decade. The returns of basic publications also mainly go to fabless design firms, smaller than manufacturing firms, which specialize in the design and integration of SoC.

${ }^{2}$ The National Science Foundation (NSF) defines basic research as a quest for understanding the fundamental aspects of phenomena and observable facts without specific immediate commercial applications in mind, and applied research as efforts aimed at meeting a recognized and specific need. 
These results are consistent with the literature on the heterogeneous incentives that firms have to perform science, and in particular basic science, when new technological opportunities arise (Malerba and Orsenigo 1996). Particularly small or young firms (in our setting, fabless firms with business models based on the continuous amelioration of system-level knowledge), appear to be better endowed to profit from (basic) science (Arora et al. 2015; Mowery 2009: Tushman and Anderson 1986). The results are also in line with the idea that entrant firms, fabless firms in our sample, are better able to adapt to radical technological change in the market than incumbent firms which "fall prey to inertia and complacency" (Henderson 1993).

The reminder of the paper is organized as follows. Section 2 provides a background on the role of science in the semiconductor industry. Section 3 presents the data. Section 4 then discusses trends in scientific publications in the sector, whereas Section 5 presents results regarding the science-value relationship. Section 6 concludes.

\section{Science in the Semiconductor Industry}

Much of the empirical research on the importance of science for innovation is confined to the pharmaceutical sector (Cockburn and Henderson 1998), where the innovation process mimics the linear model and basic science is a prerequisite for development ( $\operatorname{Lim} 2004)$. Semiconductors, instead, are a complex technology in which several components, each with their technical characteristics, have to interface. In order to integrate and design processes, semiconductor firms have to harness a diverse set of competences. Due to increasing costs of developing new technologies for the production of integrated circuits, the semiconductor sector is the second largest investor in R\&D and the most R\&D intense sector with regards to sales (National Science Board 2014). Scientific methods and practices are widespread and firms have critically contributed to the fundamental understanding of conductivity (Langlois and Steinmueller 1999; Lim 2004). Basic research in the industry covers a wide range of disciplines, ranging from solid-state physics, quantum mechanics, and basic chemistry to nanotechnology and quantum computing, and has backed fundamental shifts in dominant designs and production processes throughout the whole industry. Applied research, aimed at the improvement of manufacturing processes (Lim 2004), is highly intertwined with basic research, which allows for a more accurate appraisal of applied findings (Rosenberg 1990). ${ }^{3}$

${ }^{3}$ One pertinent example of the intertwining of basic and applied research is the development of the blue lightemitting diodes (LEDs), which was granted the Nobel Prize in Physics in 2014. The main discovery behind the blue LED is that indium gallium nitride $(\mathrm{InGaN})$ is more efficient in reflecting short-length waves than zinc selenide $(\mathrm{ZnSe})$, the current standard at the time. Leveraging on intuitions from materials science, Nakamura from Nichia Corporation developed a process to use InGaN for the mass production of blue LED and demonstrated its superior 
The semiconductor industry has developed in a cumulative fashion along a dominant architectural standard: the application of semiconductors to personal computers (the "Wintel" standard), which provided a stable interface among components. Process innovation was key in these early days when memories represented most of the production and value was captured through production-based learning. Scientific and technological efforts were therefore mostly targeted towards the amelioration of the manufacturing process (Macher 2006). The last two decades have witnessed a gradual shift from PCs to new applications related to the internet, wireless technology, and fixed multimedia (Linden and Somaya, 2003). Rapid improvements in speed through heat reduction and miniaturization have enabled the integration of large scale electronic systems within chips, the so called "systems on a chip" (SoC), widening the range of devices to which semiconductors can be applied. Firms have developed multiple architectural standards with regards to the design and compatibility of components for the new applications. The ability to integrate hardware and software and system-level knowledge have become critical factors for generating value through fast time to market and customized systems (DiBiaggio 2007; Linden et al. 2004). In the current industrial context, the range of valuable scientific competences has expanded to nanotechnology and quantum computing (Jiang et al. 2011).

While the sector is known for its strategic use of patents (Ziedonis 2004; Hall and Ziedonis, 2001), scant attention has been paid to scientific practices and publishing. Lim (2000) reports a negative relationship between basic publications and patents among researchers employed at IBM, Intel and AT\&T, suggesting a division of labor among scientists. As public research is of particular importance for fundamental progress in the sector, (Cohen et al. 2002) firms allow their researchers to publish to earn an entry ticket to the academic community and unpublished information. ${ }^{4}$ Anecdotal evidence has also highlighted disclosing research results such as minor improvements on core technologies as well as intermediate results through publications as a complementary strategy to patenting (Henkel and Pangerl 2008; Della Malva and Hussinger 2012). Finally, scientific articles are an important channel for communicating findings to stakeholders. This is especially the case for informing financial markets, as publishing is a signal of scientific competences to external stakeholders and increases beliefs about future profitability (Jong and Slavova 2014; Polidoro \& Theeke 2012). Hicks (1995) argues that "journal articles

performance with respect to $\mathrm{ZnSe}$ (Johnstone, 2007). Indium Gallium became the new standard for the production of short-length wave devices such as (blue) beams and lasers. Growth in size at Nichia was more than tenfold in just a few years. Another example is the development of copper interconnects (Lim, 2009). When IBM researchers tried to replace aluminum with copper, they found that electroplating created the most pure devices, even though this method was counterintuitive from a theoretical perspective. The development of copper interconnects was taken further by researchers at Cornell University who built on data generated by IBM.

${ }^{4}$ For example, the inventor of the blue LED, Nakamura, reported the problems he initially faced in interacting with the scientific community due to his lack of publications. Similarly, accounts on the development of the laser technology report that researchers were not able to replicate the findings reported in published articles and face-toface interaction was needed to access the tacit knowledge to replicate the experiments (Hicks, 1995). 
send messages to stockholders [...] that things are in the pipeline and so bolster a company's share price" (p. 421). In the context of the semiconductor industry, the signal might be one of being ahead in longterm developments.

Very few studies have dealt with the relationship between science and value in the semiconductor sector. Arora et al. (2015) found that the importance of performing science for firm value, despite positive, declined over time, whereas Simeth and Cincera (2015) did not find any positive significant relationship between Tobin's Q and publication activities of firms in the ICT sector at large. Both studies however did not take into account the sectoral dynamics in the sectors under analysis and the heterogeneity in the scientific findings disclosed and the different implications for future performance.

\section{Data}

We analyze the population of U.S. listed firms whose primary activity is classified under SIC code 3674 (semiconductors and related devices) and which have been operating between 1980 and 2007.5 This time frame allows us to follow the evolution of the sector from its commercial incubation up to current trends. We used Compustat North America to gather information about market value, R\&D, sales, assets, and debt. We deflated accounting figures to 1992 USD using GDP deflators. We calculated Tobin's $Q$ as the market value of equity plus the book value of debt, divided by the book value of assets. ${ }^{6}$ We identified firms' scientific publications through Thomson Reuters Web of Science, which is among the largest collections of scientific publications. We similarly matched these firms to USPTO patents using the Fall 2011 edition of PATSTAT and the name disambiguation exercise by Magerman et al. (2006). We adopted a conservative approach: author address and affiliation fields were searched for generic versions of the firms' names, and the results were manually checked for consistency. Firms were similarly matched to patents using generic firm names and manual cleanup. We used the journal-level classification created by Hamilton (2003) to differentiate between basic and applied publications. This classification has been used in previous studies (i.e. Lim 2004) as well as by national scientific organizations such as the National Science Foundation in the U.S.A. and the Observatoire des Sciences et des Techniques in France. It assigns journals to four categories along their place in the technologyscience spectrum. The categories are labelled as follows: 1. 'applied technology', 2. 'Engineering sciencetechnological science', 3. 'Applied research - targeted basic research, 4. 'Basic scientific research'

\footnotetext{
${ }^{5}$ A small number of firms have been dropped from the sample. These are firms which are listed under SIC code 3674 but which do not have the core semiconductors as main activity, and firms which are part of foreign groups. We exclude the latter because of the possibility of strategic financial reporting.

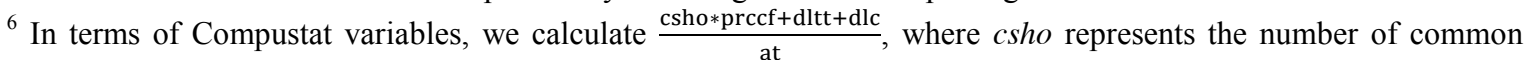
shares outstanding, prccf represents the mean average closing share price, dltt is total long-term debt, dlc is total debt in current liabilities, and at represents total assets.
} 
(Hamilton 2003, p. 5-6). For our purposes, level 4 journals were deemed basic, while others were labeled as applied.

Table 1: Summary Statistics ( $=171, \mathrm{t}=1981-2007,2,145$ obs.)

\begin{tabular}{lrrrr}
\hline Variable & Mean & \multicolumn{1}{c}{ SD } & \multicolumn{1}{c}{ Min } & \multicolumn{1}{c}{ Max } \\
\hline Tobin's Q $^{\prime}$ & 2.35 & 3.31 & 0.04 & 90.44 \\
Sales $_{t-1}$, real 1992 million USD & 628.79 & $2,120.03$ & 0.04 & $27,877.07$ \\
Sales growth & 0.23 & 1.39 & -1.00 & 52.35 \\
R\&D $_{t-1}$, real 1992 million USD & 84.02 & 276.81 & 0.00 & $4,087.61$ \\
Assets $_{t-1}$, real 1992 million USD & 905.49 & $2,947.60$ & 0.44 & $39,075.18$ \\
Patents $_{t-1}$ & 47.36 & 186.81 & 0 & 2,222 \\
Science Patents $_{t-1}$ & 21.53 & 91.67 & 0 & 1,190 \\
Publications $_{t-1}$ & 13.06 & 48.63 & 0 & 753 \\
Basic Publications $_{t-1}$ & 0.39 & 2.10 & 0 & 33 \\
Applied Publications $_{t-1}$ & 12.67 & 47.17 & 0 & 732 \\
\hline Publication Stock $_{t-1} /$ Assets $_{t-1}$ & 32.03 & 365.33 & 0 & $14,828.66$ \\
Basic Publication Stock $_{t-1} /$ Assets & 2.01 & 43.49 & 0 & $1,824.57$ \\
Applied Publication Stock $_{t-1} /$ Assets $_{t-1}$ & 16.59 & 72.49 & 0 & 974.90 \\
Patent Stock $_{t-1} /$ Assets $_{t-1}$ & 12.63 & 60.43 & 0 & $1,904.44$ \\
Science Patent Stock $_{t-1} /$ Patent Stock $_{t-1}$ & 0.32 & 0.26 & 0 & 1 \\
R\&D Stock $_{t-1} /$ Assets $_{t-1}$ & 0.63 & 0.89 & 0 & 12.53
\end{tabular}

Notes: Accounting information: sourced from Compustat. Patent indicators: sourced from Patstat 2011 edition. First year (1980) dropped because of lagged indicators. Publication indicators: sourced from Thomson Reuters Web of Science. Upper panel: Publications and patents: raw counts. Lower panel: citation-weighted publication and patents.

Our final sample is an unbalanced panel of 171 firms. The median firm is observed for 11 years. Table 1 shows descriptive statistics for the accounting, patent, and publication variables. The mean firmyear is valued at 2.35 times book value. It has 629 million USD in sales and 905 million in assets. It spends 84 million USD on R\&D, receives 47 patents ( $45 \%$ of which refer to scientific literature), and publishes 13 papers in Web of Science. The vast majority of these come from applied journals: only 3\% of publications are in basic journals.

Figure 1 plots the evolution of the average Tobin's Q throughout the sample period. We observe a slight positive trend: in 1980 the average firm was valued at 1.5 times book value, which increased to 2.8 in the 90s. In the 2000s, however, this dropped back to 2.6. There is a clear spike in Tobin's Q at the end of the 90 s, most likely representing the dot-com bubble. We capture the nonlinearities caused by this through the inclusion of year effects in the multivariate analysis of Tobin's Q. 


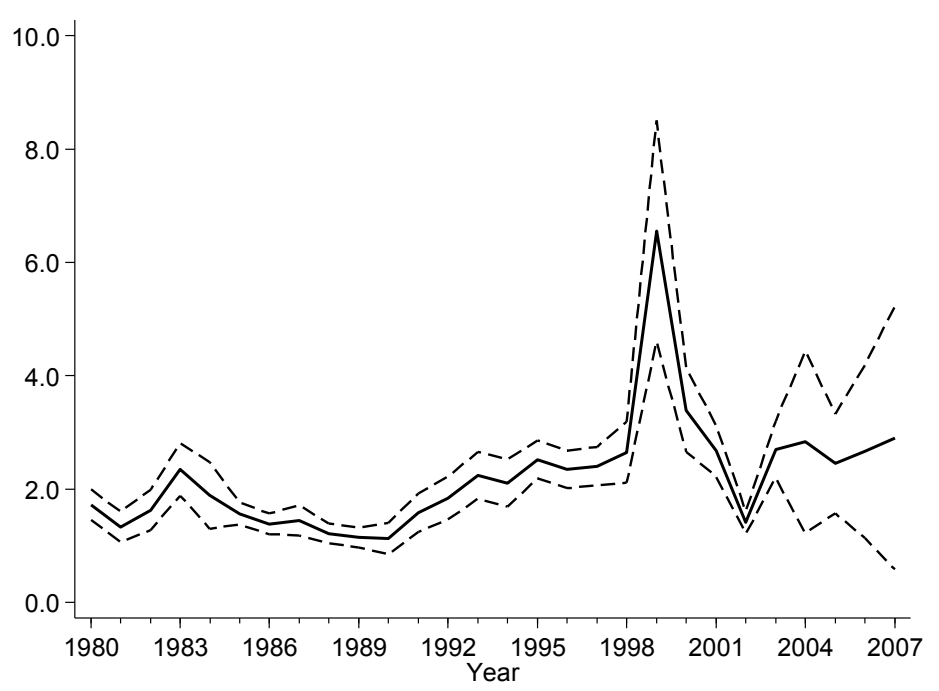

Figure 1:Average Tobin's $Q$ by year

Note: dotted lines represent $95 \%$ confidence interval

\section{The evolution of publishing and patenting}

Figure 2 plots the share of firms which patented in each year. The share of patenting firms has increased markedly throughout time, going from approximately $50 \%$ in the 1980 s to approximately $70 \%$ in the late 1990s, where it has hovered throughout the 2000s. The share of firms with patents which make use of scientific knowledge (proxied through the presence of at least one reference to scientific literature in the patent's citation list) has followed a similar evolution, from slightly more than $20 \%$ to more than $50 \%$, confirming the important role of scientific inputs for $R \& D$ in the semiconductor industry. The share of firms which publish in applied literature increased from $45 \%$ to $60 \%$ (Figure 3), roughly in line with the share of patenting firms. ${ }^{7}$ The share of firms which publish in basic journals is much smaller, but also follows a positive trend. It hovers around $7-11 \%$ of firms in the 80 s, and between $10-16 \%$ in the 2000 s. This is in line with the observations of Lim (2004) and Tijssen (2004) that basic research in semiconductors tends to be concentrated in a small number of firms.

\footnotetext{
${ }^{7}$ As the vast majority of publications is applied, the share of all publishing firms overlaps almost perfectly with the share of firms publishing in applied journals.
} 


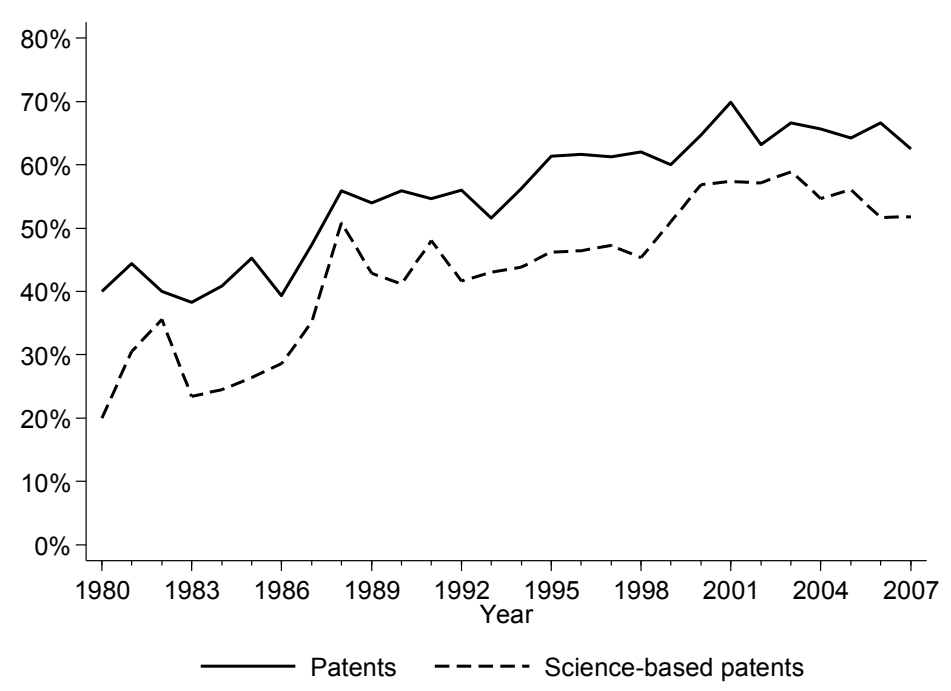

Figure 2: Share of patenting firms by year



Figure 3: Share of publishing firms per year

We formalize these trends in Table 2, which presents estimates of time trends in disclosure through publications and patents. In the baseline models (columns 1-5), all forms of disclosure follow a positive trend conditional on R\&D expenditures and sales. ${ }^{8}$ Patents grow faster than publications: patents

\footnotetext{
${ }^{8}$ These findings are in contrast to the findings of Arora et al. (2015), who report that publishing in semiconductors, especially in basic outlets, declined between 1980 and 2007. We believe that these differences can be caused by a different definition of the sector, as we rely on the SIC whereas Arora et al. utilized the firms patent portfolio to
} 
grew at a rate of 1.13 per year, while publications in total only grew at rate $1.08 .{ }^{9}$ Basic publications grew slightly stronger than patents (1.15) while applied publications grew slightly slower (1.06). In a second set of specifications (columns 6-10) we interacted the time trend with R\&D expenditures. Across all specifications, the interaction is negative and significant, indicating that the positive trend in disclosure is discounted as R\&D expenditures increase. The results show that, even though firms with higher R\&D spending produce more publications and patents than firms with lower R\&D spending, the differences between high and low spenders become smaller over time as high spenders produce less publications per dollar spent. For publications, the trend even turns negatives when R\&D expenditures are higher than the $82^{\text {nd }}$ percentile. For patents, the trend never turns negative. The case of publications is further illustrated in Figure 4 which plots the evolution of the predicted number of citation-weighted publications at different levels of R\&D expenditures throughout time. Observe the downward slope when R\&D expenditures are at the upper extreme $\left(90^{\text {th }}\right.$ percentile).

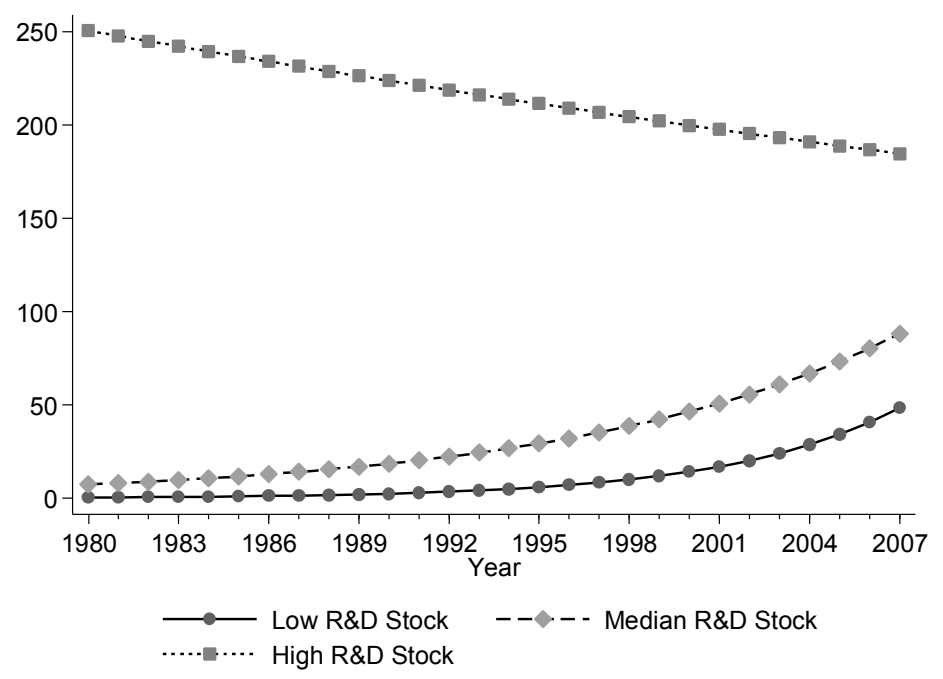

Figure 4: Convergent publication trends across different levels of $R \& D$ stock Note: Publications are citation weighted. Low R\&D: $10^{\text {th }}$ percentile. High R\&D: $90^{\text {th }}$ percentile.

assign sectors. Some of the observed differences could also be due to differences in specification. First, we choose not to apply fixed effects in this setting. Second, we model disclosure outputs through nonlinear count models while Arora et al. appear to apply a linear specification. Third, Arora et al. model publications per unit of R\&D spent, while we model publication volume while controlling for R\&D stock.

${ }^{9}$ Reported effects are incidence rate ratios, obtained by exponentiating the coefficients of a count model, and are interpreted multiplicatively. 


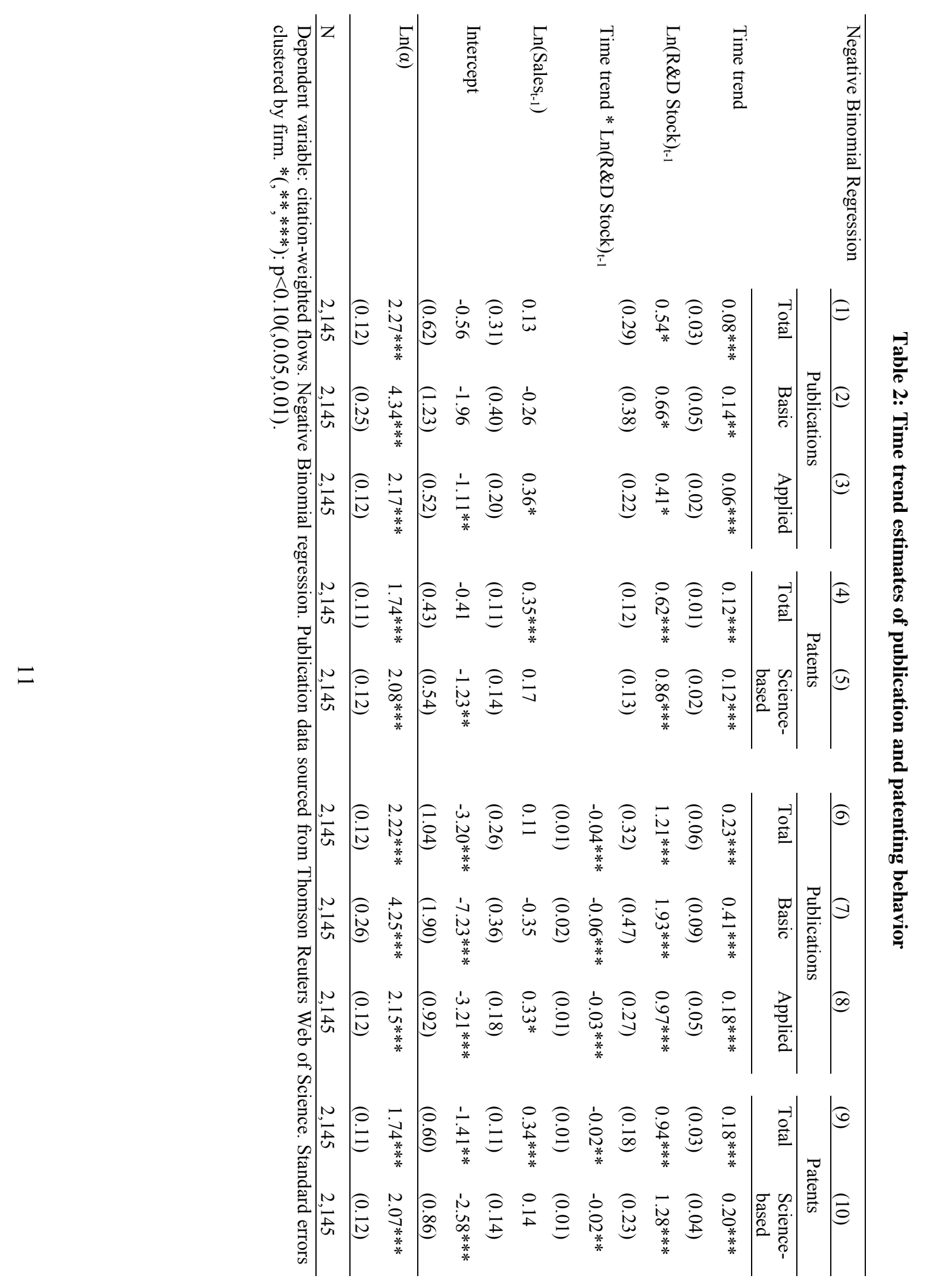




\section{The value of science}

\subsection{Event studies}

We perform a series of event studies to gather preliminary evidence on the relationship between scientific publications and firm value. ${ }^{10}$ We randomly sampled 90 applied and 90 basic publications which were published after 2002. This random selection covers 28 firms in the sample. ${ }^{11}$ We collected data from CRSPA on the stock market returns for each of the 28 firms. Abnormal returns were calculated by estimating, for each of the 180 events (taking $t_{0}$ as the date of publication), the return of the stock as a simple function of weighted market returns between $t_{-60}$ and $t_{-30}$, and then using this model to predict normal returns between $t_{-2}$ and $t_{2}$. The outcome of interest is the cumulative difference between the predicted normal returns and the observed returns for this period (the cumulative abnormal return, or CAR). We took a window around the publication date to capture any cases where knowledge of the research leaked out shortly before the date of publication. As firms in the industry are arguably worried about loss of appropriation, we are confident that knowledge will not enter the public domain long before publication in the typical case.

Table 3 shows that the average basic or applied publication does not elicit meaningful response from the stock market: the average basic publication is associated with negative cumulative abnormal return (CAR) of a quarter of a percentage point, while the average applied publication associates with a positive response of about 0.4 percentage points. Responses are dispersed such that neither is statistically significant. We can only identify a clear effect when the publications are further disambiguated into low- , medium-, and high-impact publications, The publication of a high-impact basic publication associates with an economically and statistically significant $(\mathrm{p}<0.05)$ cumulative abnormal return of approximately 2.6 percentage points, whereas the effects remain insignificant for all other categories. ${ }^{12}$ A first inspection

\footnotetext{
${ }^{10}$ Event studies have been employed in the economics of innovation literature to investigate the private value of patents in the biotechnology sector (Austin, 1993), the private value of software patents (Hall and McGarvie, 2010), and the private costs of patent trolls (Bessen et al., 2011).

${ }^{11}$ Since basic publications are only a small part of all publications, we chose to oversample these in order to be able to identify any effects. We limited the scope of the data collection to articles published after 2002 as most publications list a specific date of (first) availability only as of this date. These sets are representative in terms of year of publication, publication outlet, and citation impact for the complete sets of applied and basic publications from 2003 onwards. No ex ante restriction was placed on which firms to sample from.

${ }^{12}$ This effect might also be driven by the outlets involved: the stock market might respond to publications in highly visible prestigious journals such as Nature and Science, regardless of their ultimate impact. At the same time, these journals are cited often. There are not sufficient data points in our analysis to disentangle these effects. We nevertheless did a rudimentary robustness check for this by including a dummy that takes value 1 if the publication was in Nature (5 out of 33 publications) for the case of high-impact basic publications - there were no Science
} 
of the data therefore suggests that the stock market is more reactive to impactful publications, and rewards firms with increased belief in superior future performance.

Table 3: High-impact basic publications relate to significant positive abnormal returns

\begin{tabular}{|c|c|c|}
\hline \multicolumn{3}{|c|}{ Cumulative Abnormal Return } \\
\hline Basic publications $n(n=90)$ & Mean & Standard error \\
\hline Full sample & $-0.172 \mathrm{pp}$ & 0.626 \\
\hline Low impact & $-1.108 \mathrm{pp}$ & 1.425 \\
\hline Medium impact & $-1.018 \mathrm{pp}$ & 0.742 \\
\hline High impact & $+2.554 \mathrm{pp}$ & $1.133 * *$ \\
\hline Applied publications $(n=90)$ & Mean & Standard error \\
\hline Full sample & $+0.042 \mathrm{pp}$ & 0.463 \\
\hline Low impact & $-0.042 \mathrm{pp}$ & 0.647 \\
\hline Medium impact & $+0.520 \mathrm{pp}$ & 0.677 \\
\hline High impact & $-0.677 \mathrm{pp}$ & 0.122 \\
\hline \multicolumn{3}{|c|}{$\begin{array}{l}\text { Means indicate cumulative abnormal return to firm stock in two-day window } \\
\text { around publication }(\mathrm{t}-2 \text { to } \mathrm{t}+2) \text {, in percentage points. Cumulative abnormal } \\
\text { return present cumulative difference between observed returns and normal } \\
\text { returns in this period. Normal returns are calculated by estimating for each } \\
\text { publication the relation between the returns of the relevant firm stock using } \\
\text { value weighted market returns as a predictor. These models were trained } \\
\text { between } \mathrm{t}-60 \text { and } \mathrm{t}-30 \text {, and then used to predict normal returns between } \mathrm{t}-2 \text { and } \\
\mathrm{t}+2 \text {. Low, medium, high impact determined according to quartile of forward } \\
\text { citation count of publication as compared to other publications in basic or } \\
\text { applied group. Low: } 1^{\text {st }} \text { quartile; medium: } 2^{\text {nd }} \text { and } 3^{\text {rd }} \text {; high: } 4^{\text {th }} \text { quartile. Stars } \\
\text { indicate p-value of two-sided hypothesis test that mean cumulative abnormal } \\
\text { return is statistically different from zero: } *(, * *, * *): p<0.10(, 0.05,0.01) \text {. }\end{array}$} \\
\hline
\end{tabular}

\subsection{Multivariate analysis}

In line with extant literature, our empirical strategy is based on the firm's market value to assets ratio (Tobin's Q) (e.g. Griliches 1981; Hall et al. 2005; Simeth and Cincera 2015). This approach considers firms as bundles of assets and capabilities, including tangible assets such as plants and equipment but also intangible assets such as brand names, good will and knowledge ("hedonic model"). Existing contributions in this line of work have attempted to identify the value of knowledge assets, first through $R \& D$ investment as proxy for knowledge intensity, later incorporating (citation-weighted) patents and most recently scientific publications (among others: Griliches 1981; Deng et al. 1999; Hall et al. 2005; Belenzon 2012; Simeth and Cincera 2015; Arora et al. 2015).

publications in the random sample. Controlling for this, we still found a significant effect of 1.80 percentage points, $(\mathrm{p}<0.10)$. 
The market value of a firm is a function of tangible and intangible assets, formalized as follows:

$$
V_{i t}=q_{i t}\left(A_{i t}, \theta K_{i t}\right)^{\sigma}
$$

$V_{i t}$ represents the market valuation of firm $i, A_{i t}$ represents physical assets, $K_{i t}$ represents its intangible or knowledge capital, and $q_{i t}$ represents the valuation coefficient of assets. $\theta$ is the shadow price of knowledge assets and allows the latter to be valued differently from tangible assets. $\sigma$ allows for scale effects, and it is assumed to be one (constant returns to scale). Taking logs and moving physical assets to the left-hand side, the equation to estimate becomes:

$$
\ln \left(\frac{V_{i t}}{A_{i t}}\right)=\ln q_{i t}+\ln \left(1+\theta \frac{K_{i t}}{A_{i t}}\right)+\varepsilon_{i t}
$$

We operationalize $K_{i t}$ to include a stock of R\&D expenditures, a patent stock and (basic and applied) publication stocks. All stocks are calculated using perpetual inventory methods, applying a 15\% depreciation rate from the first available data point. The starting value of R\&D stocks is estimated assuming a $7 \%$ pre-observation growth rate and a $15 \%$ depreciation rate. Because patents and publications vary widely in their importance, we weigh both patents and publications according to forward citations (Arora et al. 2015). ${ }^{13}$ We lag all independent variables one year. We additionally include a measure for the ability of firms to embed scientific advances in technological development as the ratio of the stock of patents which include at least one reference to non-patent literature. Knowledge assets thus include:

$$
K_{i t}=\theta_{1} \frac{\boldsymbol{R}_{2} \boldsymbol{D}_{i t-1}}{A_{i t-1}}+\theta_{2} \frac{\boldsymbol{P A T}_{i t-1}}{A_{i t-1}}+\theta_{3} \frac{\boldsymbol{S C I P A T}_{i t-1}}{P A T_{i t-1}}+\theta_{4} \frac{\boldsymbol{B A S I C P U B}_{i t-1}}{A_{i t-1}}+\theta_{5} \frac{\boldsymbol{A P P L I E D P U}_{i t-1}}{A_{i t-1}}
$$

We also include a set of time dummies as well as dummies for instances in which firms show patent stocks and (basic or applied) publication stocks equal to zero. We further control for other factors affecting the valuation of firms' assets, such as (log of) sales and sales growth as larger and fastergrowing firms might be valued differently.

Table 4 presents estimates of Tobin's Q as a function of the knowledge stock of the firm through non-linear least squares (NL-LS) as well as OLS. Column 1 presents the basic version of the model and shows that most of the value from knowledge generating activities is associated to expenditures in R\&D as other measures of knowledge-related assets are hardly significant. The coefficient of patenting is statistically nonsignificant $(\mathrm{p}=0.15)$ and small, with an estimated average elasticity of $0.055 \%$. This result

\footnotetext{
${ }^{13}$ See Van Raan (2005) for an overview of the use of forward citations in the bibliometric literature and Trajtenberg (1990) for the importance of forward citations in patents.
} 
is at first surprising as previous studies found patents to be positively associated to Tobin's Q (e.g. Hall et al. 2005). ${ }^{14}$ It must be stressed however that patenting in the semiconductor industry has risen dramatically in the last years, mostly following strategic reasons, e.g. for use as bargaining chips in crosslicensing negotiations and as means to protect the freedom to operate their technologies (Ceccagnoli 2009; Ziedonis 2004; Hall and Ziedonis 2001). The coefficient of scientific publishing is also small (average elasticity: $0.012 \%$ ) and only weakly significant $(\mathrm{p}<0.10)$. The latter is in line with Simeth and Cincera (2015) who also could not confirm a strongly significant positive association between publications and Tobin's Q in the closely related ICT sector, but identified a positive publication effect among firms in general (Simeth and Cincera 2015). Arora et al. (2015) identify positive coefficients for R\&D, publication, as well as patent stocks, but through a market value setting estimated through OLS. Columns 5 through 8 show that we also obtain positive coefficients for all three if we estimate the model through OLS. The positive and significant coefficients of sales growth in all specifications indicate that financial markets attach value to firms which are able to sustain growth. In a market with slimming markups and shorter product life cycles, high levels of sales growth are only maintained by bringing products to the market place faster than competitors, which is also rated as the most effective mechanism to appropriate returns from innovation (Cohen et al. 2002).

We then distinguish between basic and applied publications in column 2. The two are valued differently: basic publications are positively associated to firm value $(\mathrm{p}<0.05)$, while the coefficient of applied publications is positive but not significant. The difference between the two coefficients is statistically significant $(\mathrm{F}(1,170)=4.15, \mathrm{p}=0.0433)$. The average elasticity of basic publication intensity with respect to Tobin's $\mathrm{Q}$ is estimated at $0.13 \%$, while that of applied publications is practically zero at $0.0084 \%$. A one standard deviation in basic publication stock per million USD in assets would result in a $2.9 \%$ increase in Tobin's Q, which represents approximately 66 million USD at the mean, assuming contemporaneous assets to be at the sample average (979.25 million USD).

This finding suggests that stock markets consider firms that publish basic science to be at an advantage in the exploitation of new findings for the introduction of new products. The positive relationship between firm value and scientific publishing activities is limited to the disclosure of discoveries in the realm of basic science, a small fraction of all scientific activities carried on by semiconductor firms.

In columns 3 and 4, we also include the share of patents which refer to scientific literature (scientific patents) as measure for the scientific orientation of the technological activities of the firms. The coefficient for scientific patents is positively associated with firm value. It is interesting to note that the

\footnotetext{
${ }^{14}$ The result is robust to different specifications, i.e. dropping publications or R\&D stocks.
} 
average elasticity of science-based patents is estimated to be larger than that of R\&D stock ( $28 \%$ versus $9.3 \%$, difference between coefficients statistically significant at $\mathrm{p}<0.10(\mathrm{~F}(1,170)=3.35, \mathrm{p}=0.0691))$. Previous studies have found that patents building on scientific results are more likely to represent technological breakthroughs, which bridge novel technological areas, and therefore with the highest economic value (Fleming 2004; Veugelers and Wang 2015). The coefficients of basic and applied publications are not affected in these specifications. Firms therefore not only benefit from the exploitation of scientific findings, but also from the development of scientific capabilities.

To sum up the results presented in Table 4, scientific publications by firms in the semiconductor sector represent a valuable form of knowledge asset, beyond the ability of firms to source from science for technological development: stock markets value those firms which actively engage in scientific research, beyond the continuous commitment to innovation, as measured by R\&D and patents. The value of scientific capabilities is mostly attributable to investments in basic science, which is associated to critical advances in new scientific challenges faced by semiconductor firms. The relevance of science for the value of corporate knowledge assets is further corroborated by the importance of science-based patents, which represent the only form of technology-based measure of knowledge asset to be positively associated with firm value.

Table 5 presents additional robustness checks by taking subsamples of the data. Columns 1 and 2 only take publishing firms into account, while 3 and 4 present similar results for firms which publish in basic literature. Columns 5 and 6 remove the top 5\% publishing firms from the sample. The results regarding basic publications become only marginally significant in these specifications, at $p<0.10$ among publishing firms and firms with basic publications, and at $p<0.05$ when top publishers are not considered), but remain present. Notably, the average elasticity of basic publishing is estimated lower among the publishing $(0.07 \%)$ or basic publishing $(0.08 \%)$ subsamples than for the general sample $(0.13 \%)$. 


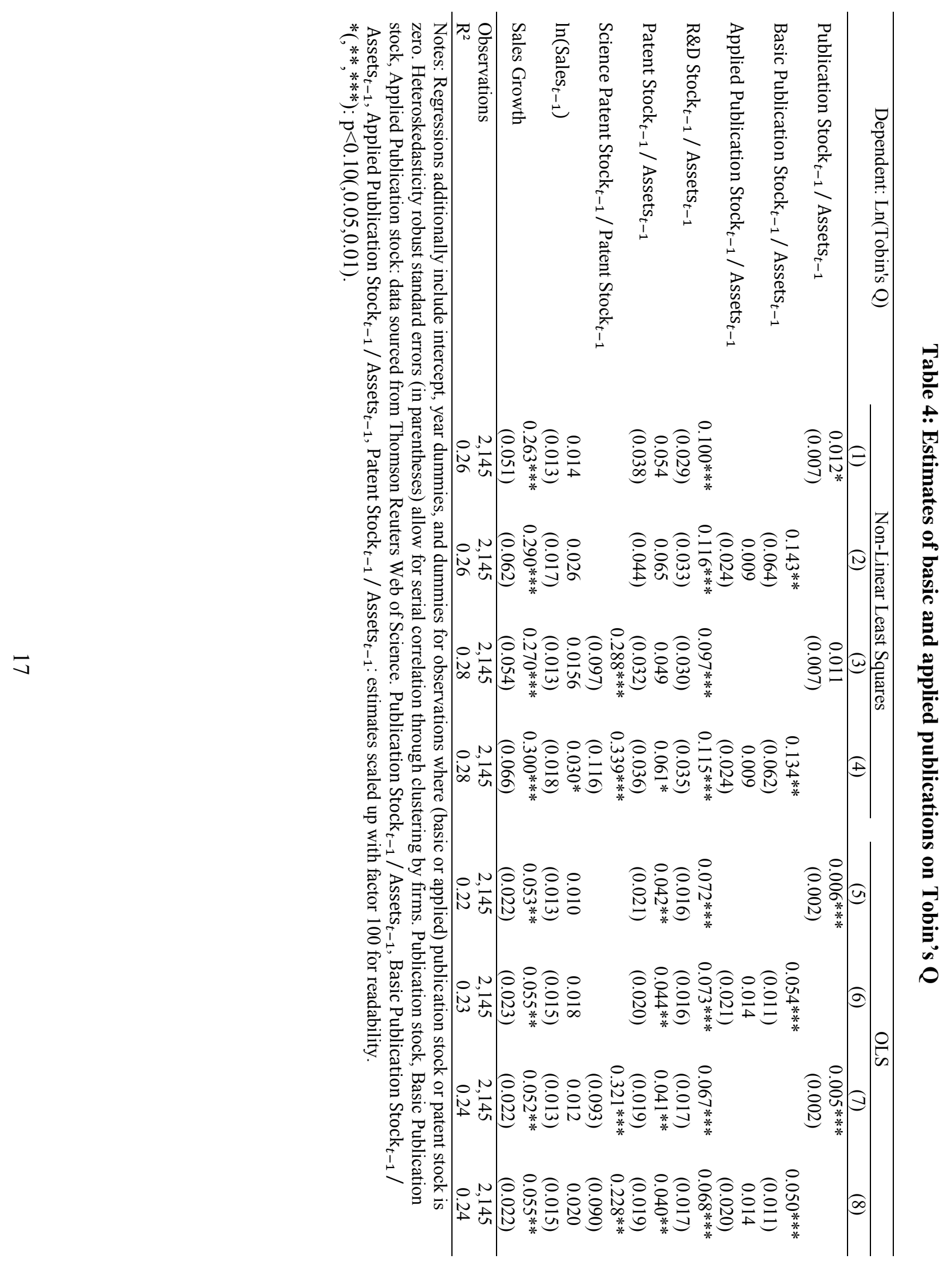




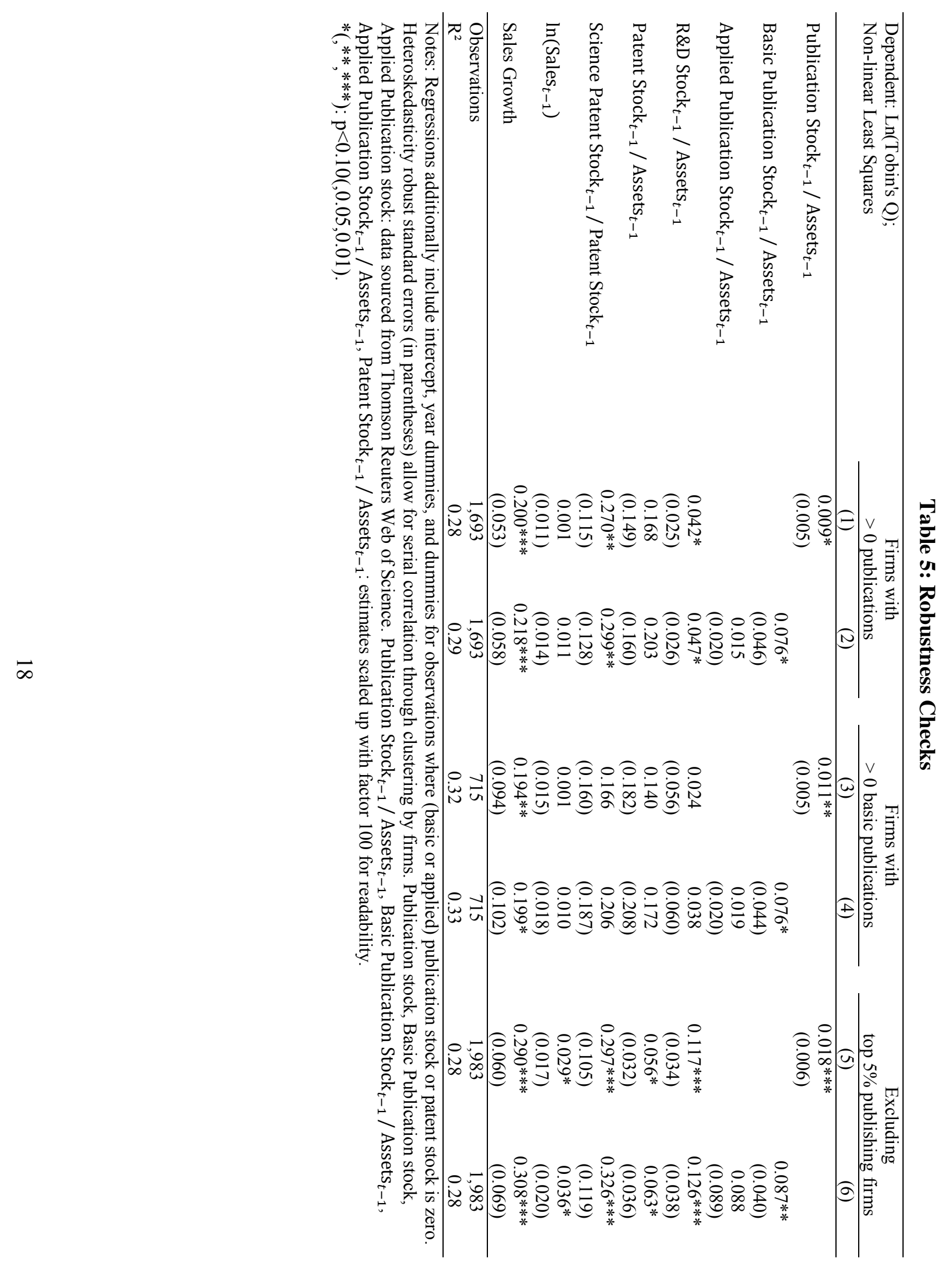




\subsection{Post-PC Era and Fabless Firms}

As of the late 1990s, the semiconductor sector has undergone a major shift towards the application of semiconductors to mobile devices, driven by the increasing miniaturization of chips. In this period fabless, or design, firms, specialized in the design of SoC, have also entered the market. In table 6 we present some heterogeneities in the value-publishing relation along these dimensions. ${ }^{15}$ The stock of basic publications has opposing effects on the value of manufacturing and design firms (columns 1-4). Scientific publications in general, and in basic journals in particular, are positively associated with the value of intangibles for design firms but negatively associated with value for manufacturing firms. The first finding is in line with the idea that design firms must marshal a new set of scientific competences in emerging fields. Mastering competences in nanotechnology and quantum computing enables the introduction of faster and less powerful products, securing therefore leadership positions in the market (Jian et al. 2011). The coefficient for scientific patents is positive and significant for design firms, confirming the relevance of science for the new entrants, which base their business models on the licensing to manufacturing companies of IP protecting fast changing designs, re-usable on a wide range of products (Linden and Somaya 2003).

The negative relation between publishing in basic scientific outlets and value for manufacturing firms, surprising at first, could be explained by both the strategic reaction of incumbent firms to the SoC paradigm and the increasing standardization in the most common production process, the CMOS. On the one hand, with the emergence of the SoC technology, some established manufacturers reacted by developing SoC internally. This led to inefficiencies related to the re-engineering of existing designs developed by third parties, and potential patent infringements, and the multiplication of costs for the development of designs covering the diverse range of products in their portfolio (Linden and Somaya 2003).

The CMOS process allows the production of several specialized products, reducing the need for specialized production processes; moreover, providers of manufacturing services (foundries with no design and own product lines) have achieved levels of manufacturing excellence in line with the highest standards (Macher et al., 1998). Moreover, profit margins in the PC market have considerably decreased with the development of a market for low-end machines. Processor manufacturers had to rely on alternative strategies for value creation such as marketing campaigns to build loyalty among customers

${ }^{15}$ The label manufacturing should be interpreted with care: in this setup, manufacturing firms can also do design, but design firms can not engage in manufacturing. 
and rapid improvements in the introduction of new processors (Linden et al., 2004). Finding that the value of manufacturing firms is positively correlated with sales growth and negatively with the stock of basic publications thus likely reflects the shorter time horizon with which financial markets have looked at manufacturing companies.

The results of columns 5 through 8 shed more light on the sectoral dynamics described above. In the first period (1980-1997), neither publications nor patents seem to affect firm value. Rather, R\&D is positive and significant. For most of the eighties, the market for semiconductors was dominated by undifferentiated products such as memory chips, and patents were important for cross-licensing agreements (Macher 2006). Only from the late 90s onwards (column 7 and 8), technology enters the value equation in the form of patents. This matches the shift to the Post-PC era of the industry, introducing differentiated products, multiple standards, and the rise of design firms. Moreover, incorporating science in products and processes, and generating new basic knowledge become positive factors in this period. Overall, these findings are in line with the work of Henderson (1993), who found that incumbent firms are less able to profit from radical technological change than entrant firms, as inertia and complacency hinder their effective adaptation to a new research paradigm. In this light, the above analysis can be interpreted as Fabless firms being more able to adapt to the new circumstances induced by the shift to the SoC paradigm and the Post-PC era of semiconductor manufacturing. 


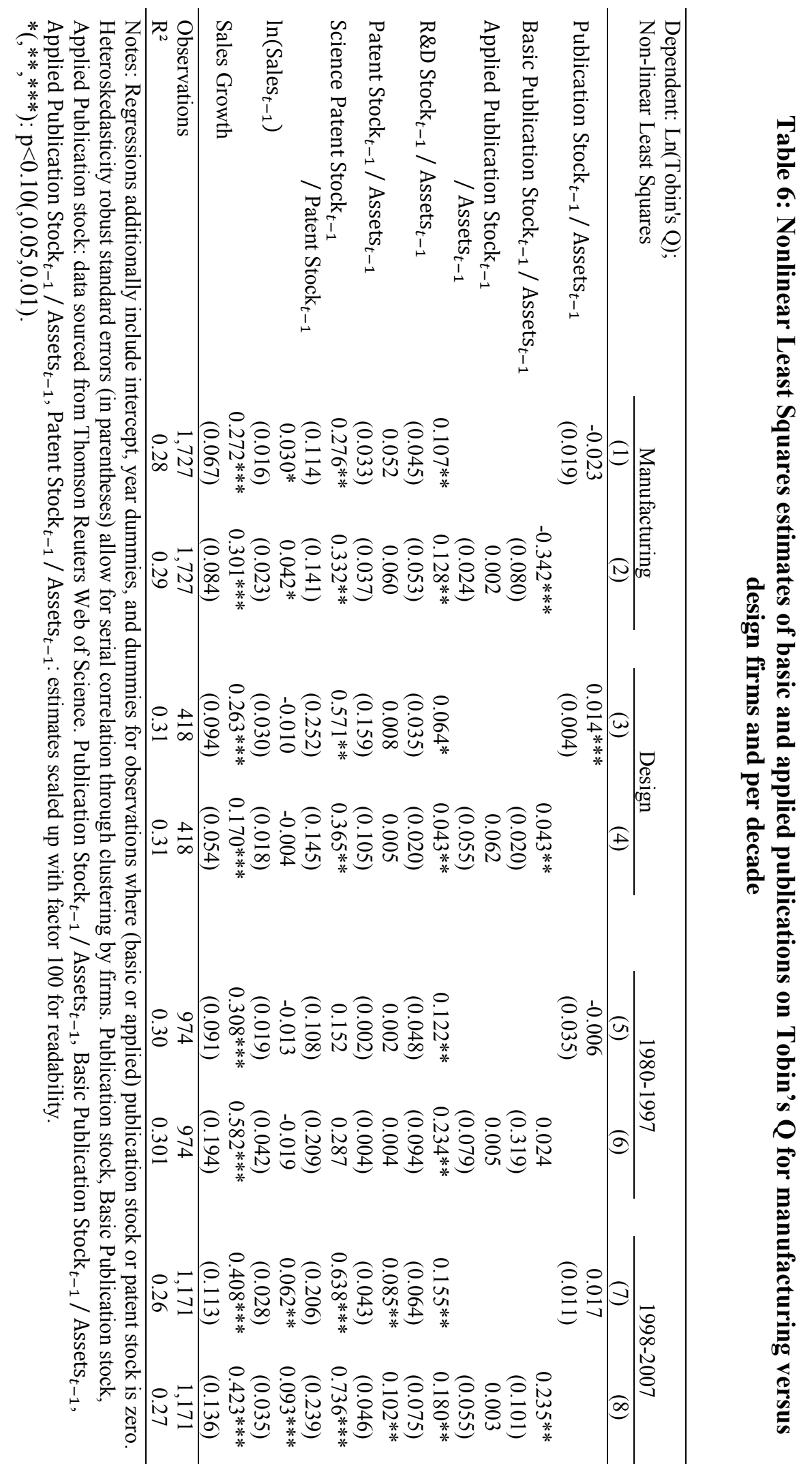




\section{Discussion and conclusions}

In this paper we investigate the relationship between scientific articles and the valuation of intangibles in publicly listed semiconductor firms in the U.S. between 1980 and 2007. The sector lends itself to the analysis as it underwent a significant structural evolution in the mid-1990s, driven by the emergence of the SoC paradigm. New scientific competences were required and new firms, leveraging on intangible assets such as patents and system-level knowledge, entered the market. We first show a positive trend in scientific publications by firms over time, mostly attributable to small firms. We then investigate the relationship between publishing and the valuation of intangibles and find a conditional positive relationship: we find that the publication of research results of basic character carries a premium for the knowledge assets of firms, whereas we do not identify a strong positive relationship between value and publishing in general. Further investigation points to a special importance of basic publishing for design firms and the post-PC era of the 2000s, which posed new scientific challenges.

This article belongs to an emerging stream of research which addresses the payoffs that firms face when engaging in the disclosure of scientific activities, to which it makes a twofold contribution. First, this article focuses on the semiconductor sector, whereas most others have either focused on a wide range of sectors (Simeth and Cincera 2015; Arora et al. 2015) or on the life sciences (Cockburn and Henderson, 1998). Focusing on the semiconductor sector has allowed us to leverage sector-wide changes to further the understanding of the phenomenon. Basic science seems to generate a value premium especially when the sector faces new scientific challenges. This is especially the case for design firms, who have received the highest premium for the successful development of basic scientific capabilities. Second, this article is one of the first to consider heterogeneity in the nature of scientific knowledge. Our analysis shows that, at least in the semiconductor industry, whether knowledge is more applied or more basic in nature makes a large difference when assessing its relation to valuation. We add to this literature by highlighting how the evolution of sectors, with the emergence of novel paradigms and the opportunities that come along, are a key driver to explain the commitment of firms to science and its relevance for the valuation of the intangibles. The promise of multiple applications for integrated circuits than PCs has led to the emergence of design firms in Semiconductors. A similar dynamics is currently leading a structural change in corporate science, where young technology intensive firms from the third industrial revolution are exploring new opportunities related to the information economy and replacing established firms in the production of corporate science (Drake 2014).

These findings shed new light on the incentives that private parties face when contributing to the stock of public knowledge. Taken together, our findings suggest that the stock market seems to value 
critical scientific contributions by firms when new opportunities, i.e. the contribution to the establishment of standards, can have long-lasting impacts on the profitability of firms. To the degree that established firms have difficulties in commercializing research (Hill and Rothaermel 2003), we find that smaller Fabless firms are better equipped to benefit from science when new opportunities arise (Henderson 1993; Tushman and Henderson 1986), and therefore have higher incentives to engage in scientific research (Drake 2014; Arora et al. 2015).

Our findings have policy implications. They suggest that during periods of decreasing public support for research, when private sponsors represent an increasing share of the research performed and financed at public laboratories (Drake 2014), policy makers should target different research areas than the ones addressed by firms, and leverage on different mechanisms to induce firms to invest in science. In particular, they should target research fields where science is far from finding immediate applications, i.e. rare diseases, research in the Bohr quadrant, when setting priorities for direct public support of research. They should make use of R\&D tax credits or subsidies for research domains within Pasteur's Quadrant. In this respect, Neicu et al (2015) have shown that R\&D subsidies have an additionality effect on the research expenses more than development. These measures can help keep a balanced portfolio of research activities and secure continuous commitment from the private sector.

This research has limitations. First, our results cannot be generalized to the economy. Second, our estimates would be more precise if we could discern between expenditures for applied and basic research, since not all results will be published. As published science is a selected subsample of results generated by the, we cannot completely separate input and output effects of basic and applied research. To our knowledge, this information is available in some versions of the Community Innovation Survey, a small fraction of which is listed. Third, future studies should deal with the firms' strategic choice of disclosure mechanisms - secrecy vs patenting vs publishing - and their antecedents, as this is likely to affect rent distributions between shareholders and scientists (Gans et al. 2013). ${ }^{16}$ One recent study has highlighted in this regard how firms in electronics have redirected their disclosure efforts towards patenting, away from non-protected forms of disclosure (Bhaskarabhatla \& Hedge 2014). Finally, our study only focuses on the reaction of stock markets to the publication of science by firms. Future research should extend this line of research by looking at the implications of scientific publications for competitors as well as members of the value chain (Alexy et al. 2013).

\footnotetext{
${ }^{16}$ An interesting example of this is found in blue LED technology: Nichia kept secret the technology to work the Gallium, patented the processes to develop the components for the blue LED structures and published the results regarding the emitting properties of their products to prove their superiority with respect to Zinc Carbide (Johnstone, 2007). Exploring the contents of various disclosure channels could form an interesting topic for future research.
} 


\section{References}

Adams, J. D., \& Clemmons, J. R. 2008. The origins of industrial scientific discoveries. NBER Working Paper 13823.

Alexy O., George G., Salter A. 2013. Cui bono? The selective revealing of knowledge and its implications for innovative activity. Academy of Management Review, 38(2): 270-291

Arora, A., Belenzon S., Patacconi A. 2015. Killing the golden goose? The decline of Science in corporate R\&D. NBER Working Paper 20902

Arora, A., Gambardella, A. 1994. The changing technology of technological change: general and abstract knowledge and the division of innovative labour, Research Policy, 23(5): 523-532.

Arrow, K. 1962. Economic welfare and the allocation of resources for innovation. In R. R. Nelson (Ed.): The rate and direction of inventive activity: 609-626. Cambridge (MA): NBER Books.

Austin, .D. 1993. An event-study approach to measuring innovative output: the case of biotechnology. American Economic Review Papers and Proceedings, 83(2): 253-258.

Belenzon, S. 2012. Cumulative Innovation and Market Value: Evidence from Patent Citations. The Economic Journal, 122: 265-285.

Bessen, J., Ford, J., Meurer, M. J. 2011. The private and social costs of patent trolls. Regulation, 34, 2635 .

Bhaskarabhatla, A., Hegde, D. 2014. An organizational perspective on patenting and open innovation. Organization Science, 25(6): 1744-1763.

Breschi, S., Catalini, C. 2010. Tracing the linkages between science and technology: an exploratory analysis of the research networks among scientists and inventors. Research Policy, 39(1): 14-26.

Ceccagnoli, M. 2009. Appropriability, preemption, and firm performance. Strategic Management Journal, 30(1): 81-98.

Cincera, M., Dratwa, D. 2011. Determinants of scientific production: an empirical study of the world's top R\&D companies. Mimeo.

Cockburn, I., Henderson, R. 1998. Absorptive capacity, coauthoring behavior, and the organization of research in drug discovery. The Journal of Industrial Economics, 46(22): 157-182.

Cohen, W., Levinthal, D. 1990. Absorptive capacity - a new perspective on learning and innovation. Administrative Science Quarterly, 35(1): 128-152.

Cohen, W., Nelson R., Walsh J. 2002. Links and impacts: the influence of public research on industrial R\&D. Management Science, 48(1): 1-23.

Della Malva, A., Hussinger, K. 2012. Corporate science in the patent system: an analysis of the semiconductor industry. Journal of Economic Behavior \& Organization, 84(1): 118-135.

Della Malva, A., Kelchtermans S., Leten B., Veugelers R. 2015. Basic Science as a prescription for breakthrough inventions in the pharmaceutical industry. Journal of Technology Transfer, 40(4): 670-695.

Deng, Z., Lev, B., Narin, F. 1999. Science and technology as predictors of stock performance. Financial Analysts Journal, 55(3): 20-32.

Dibiaggio, L. (2007). Design Complexity, Vertical Disintegration and knowledge organization in the semiconductor industry. Industrial and Corporate Change, 16(2): 239-267. 
Drake, N. 2014. Basic science finds corporate refuge. Science, 509: 19-19.

Fleming L., Sorenson, O. 2004. Science as a map in technological search. Strategic Management Journal, 25(8-9): 909-928.

Gans J., Murray, F., Stern, S. 2013. Contracting over the disclosure of scientific knowledge: intellectual property and academic publication. NBER Working paper no. 19560.

Griliches, Z. 1981. Market value, R\&D, and patents. Economic Letters, 7(2): 183-187.

Hall, B., McGarvie, M. 2010. The private value of software patents. Research Policy 39, 994-1009.

Hall, B., Ziedonis, R. 2001. The patent paradox revisited: an empirical study of patenting in the U.S. semiconductor industry, 1979-1995. RAND Journal of Economics, 32(1): 101-128.

Hall. B., Jaffe, A., Trajtenberg, M. 2005. Market value and patent citations. RAND Journal of Economics, 36(1): 16-38.

Hamilton, K. 2003. Subfield and level classification of journals. CHI report 2012-R. Chi Research Inc.

Henderson, R. 1993. Underinvestment and incompetence as responses to radical innovation: Evidence from the photolithographic alignment equipment industry. RAND Journal of Economics, 24(2): 248-270.

Henkel, J., Pangerl, S. 2008. Defensive publishing - an empirical study. DRUID Working Paper no. 0804.

Hicks, D. 1995. Published papers, tacit competencies and corporate management of the public/private character of knowledge. Industrial and Corporate Change, 4(2): 401-424.

Hill, C. W., Rothaermel, F.T. 2003. The performance of incumbent firms in the face of radical technological innovation. Academy of Management Review 28(2): 257-274.

Jiang, L., Tan, J., Thursby, M. 2011. Incumbent firm invention in emerging fields: evidence from the semiconductor industry. Strategic Management Journal, 32(55): 55-75.

Johnstone, R. 2007. Brilliant!: Shuji Nakamura and the Revolution in Lighting Technology. Prometheus Books, Amherst, N.Y.

Jong, S., \& Slavova, K. 2014. When publications lead to products: The open science conundrum in new product development. Research Policy, 43(4): 645-654. doi:10.1016/j.respol.2013.12.009

Langlois, R. N., Steinmueller, W. E. 1999. The evolution of competitive advantage in the worldwide semiconductor industry, 1947-1996. In: Mowery, D. C., Nelson, R. R. (eds.): Sources of Industrial Leadership: Studies of Seven Industries, 19-78.

Lim, K. 2000. Basic research, applied research, and innovation in the semiconductor and pharmaceutical industries. Doctoral Dissertation.

Lim, K. 2004. The relationship between research and innovation in the semiconductor and pharmaceutical industries (1981-1997). Research Policy, 33(2): 287-321.

Lim, K. 2009. The many faces of absorptive capacity: spillovers of copper interconnect technology for semiconductor chips. Industrial and Corporate Change, 18(6): 1249-1284.

Linden, G., Brown G., Appleyard M. 2004. The Net World Order's Influence on Global Leadership in the Semiconductor Industry. In Kenney, M., Florida R. (eds.), Locating Global Advantage: 232-257. Stanford, CA: Stanford University Press, pp.

Linden, G., Somaya D. 2003. System-on-a-chip integration in the semiconductor industry: Industry structure and firm strategies. Industrial and Corporate Change, 12(3): 545-576. 
Macher, J. 2006. Technological development and the boundaries of the firm: a knowledge-based examination in semiconductor manufacturing. Management Science, 52(6): 826-843.

Macher, J., D. Mowery, D. Hodges. 1998. Back to Dominance? U.S. Resurgence in the Global Semiconductor Industry. California Management Review, 41(1): 107-136.

Magerman, T., Van Looy, B., Song, X. 2006. Data production methods for harmonized patent indicators: patentee name harmonization. Eurostat Working Papers and Studies.

Malerba F., Orsenigo L. 1996. Technological Regimes and Sectoral Patterns of Innovation. Industrial and Corporate Change, 6(1): 83-117.

Mowery, D. 2009. Plus ca change: Industrial R\&D in the "third industrial revolution". Industrial and Corporate Change, 18(1): 1-50.

National Science Board. 2014. Science and Engineering Indicators 2014. Arlington VA: National Science Foundation (NSB 14-01).

Neicu, D., Teirlinck P., and Kelchtermans S. 2015. Dipping in the policy mix: Do R\&D subsidies foster behavioral additionality effects of R\&D tax credits? Economics of Innovation and New Technology, 1-22.

Nelson, R. 1959. The simple economics of basic scientific research. Journal of Political Economy, 67(3): 297-306.

Pénin, J. 2007. Open knowledge disclosure: an overview of the evidence and economic motivations. Journal of Economic Surveys, 21(2): 326-348.

Polidoro, F., Theeke, M. 2012. Getting competition down to a science: the effects of technological competition on firms' scientific publications. Organization Science, 23(4): 1135-1153.

Rosenberg, N. 1990. Why do firms do basic research (with their own money)? Research Policy 19(2): $165-174$.

Simeth, M., Cincera, M. 2015. Corporate science, innovation, and firm value. Management Science, forthcoming.

Tijssen, R. 2004. Is the commercialization of scientific research affecting the production of public knowledge? Global trends in the output of corporate research articles. Research Policy, 33(5): 709-733.

Trajtenberg, M. 1990. A penny for your quote: patent citations and the value of innovations. The Rand Journal of Economics 21(1): 172-187.

Tushman, M. L., Anderson, P, 1986. Technological discontinuities and organizational environments. Administrative Science Quarterly, 31(3): 439-465.

Van Raan, A. 2005. Measuring science. In: Moed, H., Glänzel, W., Schmoch, U. (eds.). Quantitative science and technology research: the use of publication and patent statistics in studies of S\&T systems: 19-50. Kluwer academic publishers, Dordrecht.

Veugelers, R., Wang, J. 2015. Novel Science for Industry? KU Leuven Faculty of Economics and Business Working Paper MSI_1513.

Ziedonis, R. 2004. Don't fence me in: fragmented markets for technology and the patent acquisition strategies of firms. Management Science 50: 804-820. 